\title{
A global analysis on the effect of temperature, socio-economic and environmental factors on the spread and mortality rate of the COVID-19 pandemic
}

\author{
Mizanur Rahman $^{1}$ (D) Mahmuda Islam ${ }^{1} \cdot$ Mehedi Hasan Shimanto $^{1}$. \\ Jannatul Ferdous ${ }^{1}$ - Abdullah Al-Nur Shanto Rahman ${ }^{1}$. Pabitra Singha Sagor ${ }^{1}$. \\ Tahasina Chowdhury ${ }^{1}$
}

Received: 11 July 2020 / Accepted: 30 September 2020 / Published online: 6 October 2020

(c) Springer Nature B.V. 2020

\begin{abstract}
We performed a global analysis with data from 149 countries to test whether temperature can explain the spatial variability of the spread rate and mortality of COVID-19 at the global scale. We performed partial correlation analysis and linear mixed effect modelling to evaluate the association of the spread rate and motility of COVID-19 with maximum, minimum, average temperatures and diurnal temperature variation (difference between daytime maximum and night-time minimum temperature) and other environmental and socioeconomic parameters. After controlling the effect of the duration since the first positive case, partial correlation analysis revealed that temperature was not related with the spatial variability of the spread rate of COVID-19 at the global scale. Mortality was negatively related with temperature in the countries with high-income economies. In contrast, diurnal temperature variation was significantly and positively correlated with mortality in the lowand middle-income countries. Taking the country heterogeneity into account, mixed effect modelling revealed that inclusion of temperature as a fixed factor in the model significantly improved model skill predicting mortality in the low- and middle-income countries. Our analysis suggests that warm climate may reduce the mortality rate in high-income economies, but in low- and middle-income countries, high diurnal temperature variation may increase the mortality risk.
\end{abstract}

Keywords Temperature $\cdot$ Socio-economic and environmental factors $\cdot$ COVID-19 pandemic $\cdot$ Mortality $\cdot$ Partial correlation analysis $\cdot$ Mixed effect modelling

Mizanur Rahman

mizan-for@sust.edu

1 Department of Forestry and Environmental Science, Shahjalal University of Science and Technology, Sylhet 3114, Bangladesh 


\section{Introduction}

COVID-19 has become a global concern since the pandemic situation caused by COVID19 posed an unprecedented threat to the world. The pandemic has already brought changes in social, economic, political, cultural and environmental aspects around the world. COVID-19 is a respiratory illness caused by the new coronavirus "Severe acute respiratory syndrome coronavirus 2 (SARS-CoV-2)" (Gorbalenya et al. 2020; Shereen et al. 2020). According to the World Health Organization (WHO), the first case of COVID-19 has been reported in December 2019. As shown by the COVID-19 dashboard by the Center for Systems Science and Engineering (CSSE) at Johns Hopkins University, COVID-19 caused 346,700 death with a total of 5,519,878 confirmed cases (as of 26th May 2020, 19.00 GMT+6.00) (Dong et al. 2020).

With a start from China, COVID-19 outbreak has been observed in the high latitude (Temperate) region, leading scientists to assume that COVID-19 outbreak and death are linked with low temperature. The first study which tested the effect of temperature and humidity on the COVID-19 associated with mortality reported that temperature had a positive link with the mortality in Wuhan, China (Ma et al. 2020). The relationship between ambient temperature and COVID-19 infection has been investigated in China with the hypothesis that warmer weather may reduce the case count of COVID-19 (Xie and Zhu 2020). Analysing data from 122 cities the study found no evidence of decline in confirmed cases with increasing temperature, rather found a positive association between temperature and COVID-19 confirmed cases (Xie and Zhu 2020). The assumption of suppression of COVID-19 due to warmer temperature is probably based on the optimal temperature range of SARS-CoV-2 transmission (13-24 ${ }^{\circ} \mathrm{C}$ ) as confirmed by Anis (2020). It is important to note that this preprint has not been peer reviewed and thus requires caution during interpretation of the results therein. Nevertheless, it is obvious that the temperature effect on COVID-19 transmission and mortality is not consistent across the world.

Temperature was negatively associated with the confirmed cases of COVID-19 in Turkey, Brazil and China (Liu et al. 2020; Prata et al. 2020; Şahin 2020). In contrast to these findings, many studies reported a positive relationship between temperature and COVID19 transmission in several countries (Bashir et al. 2020; Tosepu et al. 2020; Xie and Zhu 2020). Some of the recent studies, however, reported no significant role of temperature on COVID-19 transmission (Ahmadi et al. 2020; Iqbal et al. 2020; Yao et al. 2020). The available scientific evidence thus provides non-consistent results that call for further studies at the global scale. A country's socio-economic and environmental factors may also be associated with the confirmed cases. For example, COVID-19 transmission was found to have low sensitivity to temperature and high sensitivity to population size (Jahangiri et al. 2020). These findings highlight the importance of socio-economic and environmental factors to be considered while testing climatic influence on COVID-19 outbreak and mortality. The present study aims at investigating the link between temperature and the spatial variability of COVID-19 spread and mortality at the global scale. We answered the following research questions:

1 Can temperatures explain the spatial variability of the rate of spread and mortality of COVID-19 at the global scale?

2 Does warm climate suppress the rate of spread and mortality of COVID-19?

3 Which socio-economic and environmental factors are linked with the spread and mortality rate of COVID-19? 


\section{Materials and methods}

\subsection{Main characteristics of COVID-19}

COVID-19 caused by SARS-CoV-2 has been declared as a pandemic during the second quarter of March this year. SARS-CoV-2 belongs to the Coronaviridae family under the order Nidovirales. Coronavirinae (one of the two subfamilies of Coronaviridae) consists of four genera including Alphacoronavirus, Betacoronavirus, Gammacoronavirus and Deltacoronavirus. SARS-CoV-2 is a single-strand RNA virus which belongs to the genus Betacoronavirus and is able to infect human ( $\mathrm{Lu}$ et al. 2020). Based on the phylogenetic classification of SARS-CoV-2 genome, the researchers indicate bat as the original host of SARS-CoV-2 (Lu et al. 2020; Zhou et al. 2020). Although it was reported that COVID-19 transmitted from animal to human ( $\mathrm{Li}$ et al. 2020), human to human and person to person transmission mainly through respiratory droplets have been reported around the world (Chan et al. 2020; Yu et al. 2020). The mean incubation period widely varied between 5 and 24 days (Chu et al. 2020; Huang et al. 2020; Li et al. 2020). Males are found to be more susceptible to COVID-19 than females (Jin et al. 2020). Peoples of 60+ age were reported to be affected more by COVID-19, whereas the rate of infection in children was low (Davies et al. 2020). The usual symptoms of COVID-19 include high fever, sore throat, cough, shortness of breath, dyspnoea, chest pain, fatigue and myalgia, while the less frequent includes dizziness, headache, diarrhoea, abdominal pain, vomiting and nausea (Harapan et al. 2020). Unlike SARS-CoV and MERS-CoV, SARS-CoV-2 prefers infecting lower respiratory than the upper respiratory tract (Huang et al. 2020).

\subsection{Data acquisition}

The data on total confirmed cases, total death counts and total test performed in 149 countries (Fig. 1) were collected from three complementary sources viz: World Health

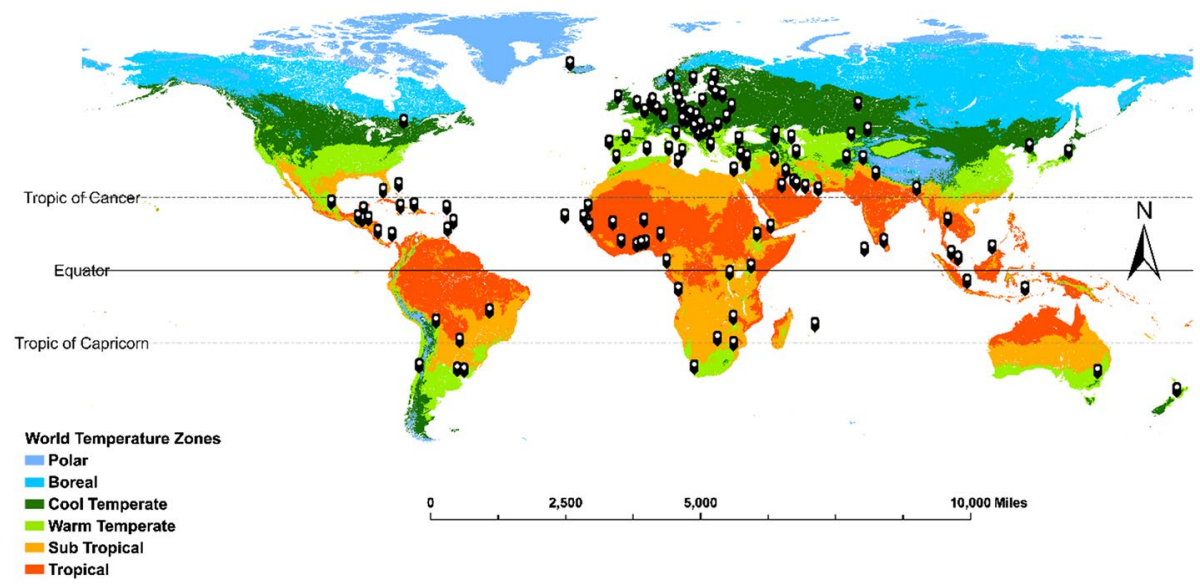

Fig. 1 World temperature zone map developed based on the six temperature domains given by Sayre et al. (2020) showing the location of 149 countries for which the spread and mortality rate of COVID-19 were analysed 
Organization (WHO), COVID-19 dashboard by the Center for Systems Science and Engineering (CSSE) at Johns Hopkins University (JHU) and Worldometers.info website. WHO is the leading global organization providing guidelines and reliable information related to COVID-19. Johns Hopkins University has been playing key roles in providing realtime data on COVID-19 and has become a reliable data source for the researchers by this time. Worldometer is a US-based independent digital media run by an international team of researchers, developers and volunteers. The main goal of this organization is to make world statistics available in a time relevant format to the global audience. It was selected as one of the best free reference websites by the world's oldest and largest library association "American Library Association (ALA)". Data were retrieved on 11th May 2020.

The data on the socio-economic parameters including population density, GDP growth rate, GDP per capita, population growth rate, life expectancy, percentage of population over 60 years, health expenditure, physicians per thousand people and environmental variables including number of threatened species, forested area, $\mathrm{CO}_{2}$ emission, protected area percentage of the forested area were collected from United nation country database (data retrieved on 13th May 2020). We included the socio-economic variables in our study because a country's socio-economic condition directly reflects the country's health care system. A good health care system allows taking appropriate management of any pandemic like COVID-19. Peoples' migration may promote the spread rate of COVID-19 (Song et al. 2020). Nevertheless, the migration data during the COVID-19 pandemic were not available for all the countries. Therefore, we did not include this in our analysis.

Air quality of a city or region may be related with the health condition of the people of that region particularly the condition of respiratory system. Since the air quality index data were not available for all the countries we studied, we took forested area, $\mathrm{CO}_{2}$ emission, protected area percentage, number of threatened species as the proxies for air quality indicators. The specific management strategies such as lockdown, increased facilities for PCR testing may help tackle COVID-19 pandemic. Particularly, lockdown was found to suppress COVID-19 both in developed and developing countries (Atalan 2020; Shammi et al. 2020). However, we did not include management intervention into our analysis since the intervention starting time, duration and nature were not uniform across the 149 countries we analysed.

Daily maximum, minimum and average temperature data for the period from 1st Jan 2020 to 10th May 2020 were collected from The Weather Channels (https://www.weath er.com/) and from the Weather Underground (https://www.wunderground.com/). Diurnal temperature variation was calculated from the difference between the daytime maximum temperature and night-time minimum temperature of the same day. We did not include humidity and wind speed into our analysis since the three variables (wind speed, humidity and temperature) are interconnected and are subjected to collinearity problem.

\subsection{Data preparation and statistical analyses}

We collected data on selected variables (Table 1) from a total of 149 countries. Because a country's health system is linked with the economic condition, we classified the infected countries into two groups: 1. countries with high-income economies 2. countries with low- and middle-income economies. We followed the World Bank's country classification 2020 for this grouping. We collected data on number of cumulative tests performed by individual country and the total confirmed cases in each country until 10th May 2020. To 
Table 1 List of climatic, environmental, socio-economic and COVID-19 parameters used in the study and their description

\begin{tabular}{|c|c|c|}
\hline Factors & Parameters used & Description \\
\hline \multirow[t]{2}{*}{ COVID-19 } & Infected/tested & Rate of spread (\%) \\
\hline & Mortality & Mortality rate $(\%)$ \\
\hline \multirow[t]{4}{*}{ Temperatures } & TempMax & Maximum temperature $\left({ }^{\circ} \mathrm{C}\right)$ \\
\hline & TempMin & Minimum temperature $\left({ }^{\circ} \mathrm{C}\right)$ \\
\hline & TempAvg & Average temperature $\left({ }^{\circ} \mathrm{C}\right)$ \\
\hline & TempMax-Min & Maximum-minimum temperature $\left({ }^{\circ} \mathrm{C}\right)$ \\
\hline \multirow[t]{4}{*}{ Environmental } & ForestArea & Forested area ( $\%$ of land area) \\
\hline & ProtArea & Protected area $(\%)$ \\
\hline & ThretSp & Threatened species (number) \\
\hline & $\mathrm{CO}_{2}$ Emis & $\mathrm{CO}_{2}$ emission estimates (million tons) \\
\hline \multirow[t]{7}{*}{ Socio-economic } & PopDen & Population density (per $\left.\mathrm{km}^{2}, 2019\right)$ \\
\hline & GDP Growth & Gross domestic product (GDP) growth rate (annual \%) \\
\hline & PopGrow & Population growth rate (average annual \%) \\
\hline & HealthExpen & Health expenditure (\% of GDP) \\
\hline & Age60+ & Population age distribution $(60+$ years old, $\%)$ \\
\hline & PhysPerTho & Health physicians (per 1000 pop.) \\
\hline & LifeExped & Life expectancy at birth (years) \\
\hline
\end{tabular}

parameterize the rate of spread, we calculated number of positive cases per 100 tests performed as follows:

$$
\text { Rate of } \operatorname{spread}(\%)=(\text { Total confirmed cases } \div \text { Total test performed }) \times 100 \%
$$

Calculating the rate of spread in this way instead of using only the total confirmed cases allows to consider the influence of varying number of tests performed by each country on the total confirmed cases. Generally, the cumulative number of confirmed cases has an increasing trend until the positive case becomes zero. This increasing trend does not necessarily mean the rising intensity of the COVID-19 outbreak. Thus, the way we calculated the rate of COVID-19 spread provides an estimate which is independent of the variation of the number of tests performed among the countries. Likewise, mortality was calculated for each country as follows:

$$
\text { Mortality }(\%)=(\text { Number of total death count } \div \text { Total infected people }) \times 100 \%
$$

We calculated the mean value of the daily minimum, maximum and average temperature averaged over the period from 1st January 2020 to 10th May 2020, the common period for which the rate of spread and mortality was calculated. In this way, we made sure that the climatic data are representative of the contemporary pandemic condition. Climatic parameters may cause lag effect of three days on the case count (Liu et al. 2020). We excluded the daily temperature values for the last 3 days before 10th May 2020 and tested if this affects our results. We found no changes in our overall results due to this lag test.

It is likely that the duration since the first positive case may affect the rate of spread and mortality. The case counts and mortality both follow an initial increasing trend until they reach the peak and then decline (Jia et al. 2020). It is thus necessary to control the effect of 
the duration after the first positive case on the rate of spread and mortality. We performed a partial correlation analysis to test the relation of the rate of spread and mortality with a set of explanatory variables listed in Table 1 . The advantage of the partial correlation over the traditional bivariate Pearson correlation is that we can rule out the undesired effect of some factors by taking them as controlling factors. In our analyses, we took the duration after the first positive case as a controlling factor which allowed to control the effect of temporal trend on the response variable. Besides, we performed the correlation analysis using 1000 bootstrapped correlations by random extraction with replacement of values. This bootstrapping approach allows to measure the accuracy of the confidence interval to the sample estimates.

Then, we performed linear mixed effect modelling with significantly related variables resulted from the partial correlation analysis. It is worth mentioning that health expenditure and physicians per thousand people were highly correlated with $60+$ aged people resulting in collinearity problem. As such, these two variables were excluded from the mixed effect models. We ran two sets of mixed effect models for each of the groups of countries (low-income countries, and low- and middle-income countries) and all the infected countries together (global). The first sets were run without temperature and the second sets with temperature. Comparing two sets of model's outputs will allow to test if temperature has improved the model performance. Model performance was evaluated by comparing the Akaike information criteria (AIC), model with lower AIC value has better skill for prediction. This mixed effect modelling approach estimates both fixed and random effects and allows to take country's heterogeneity into account while testing the effects of explanatory variable on the response variables. We considered temperature and other response variables as the fixed factors and country Id as the random factors in our mixed effect models.

Before the analyses were performed, the normality of data distribution of all the response and explanatory variables was tested using Kolmogorov-Smirnov test. In case of not-normal distribution, data were log-transformed to get a normal distribution. After checking the distribution, the outliers were excluded from the analysis. For example, Algeria and Gavon were left out of the analyses since these countries fell outside the normal range of values. Partial correlation analysis and the normality tests were performed using SPSS version 25.0 (IBM Corp. 2017). Mixed effect modelling was performed using the "lme" function of the "nlme" package in $R$ statistical environment. To evaluate the variation explained by the fixed factors, we calculated marginal $R^{2}$ using the MuMln package in R (R Development Core Team 2019).

\section{Results}

Both mortality and the rate of spread were low in Asian, Australia and some African countries (Fig. 2). The highest spread rate was observed in Equatorial Guinea (51\%) followed by Guinea-Bissau and Brazil (48\%) until 10th May 2020. The highest mortality was observed in Sint Maarten Dutch (20\%) followed by Belgium and Yemen (16\%). The lowest spread rate was found in Venezuela, while the mortality was close to zero in Qatar. It is important to note that the countries where either the mortality or the spread rate was zero were excluded from further analyses.

Globally, mortality was negatively related with population growth rate $(r=-0.27$, $p<0.01)$ and positively related with the percentage of people over 60 years old $(r=0.34$, $p<0.001$ ) (Fig. 3). However, the rate of COVID-19 spread was not associated with any 


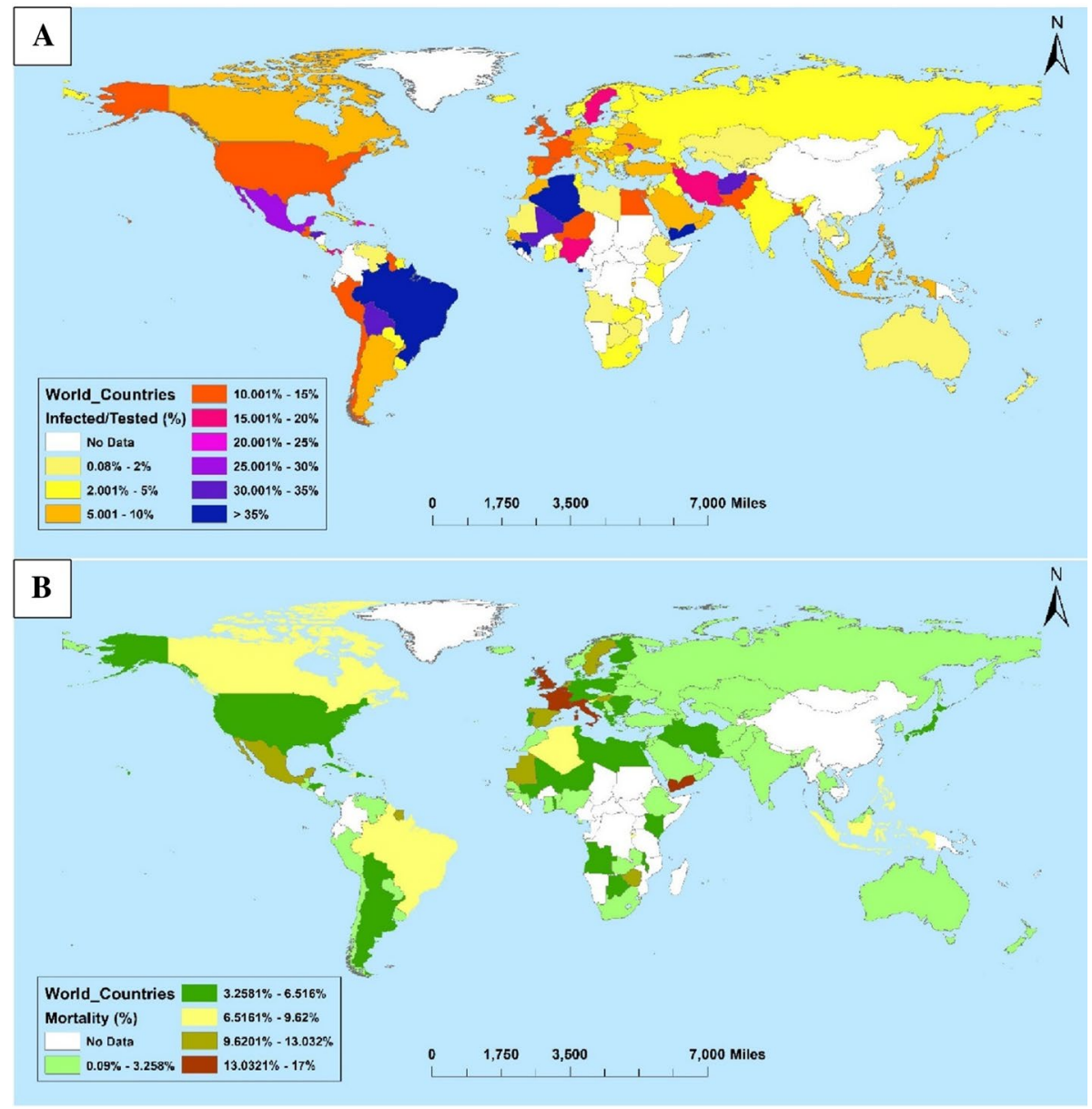

Fig. 2 Spatial variability of the rate of spread (a) and mortality (b) of COVID-19 at the global scale

of the climatic, environmental and socio-economic parameters. When analysed with the countries having high-income economies, the spread rate was negatively linked with GDP growth rate $(r=0.30, p<0.05)$. The mortality in high-income countries was associated with multiple climatic, environmental and socio-economic parameters (Fig. 3). Temperatures (Max, Min and Avg) were negatively connected with the mortality in high-income countries $(p<0.05)$, whereas health expenditure, number of health physician and percentage of people over 60 years were strongly positively linked with mortality $(p<0.001)$. A strong negative relation between population growth rate and mortality was found in the high-income countries $(r=-0.53, p<0.001)$. Forested area had a positive link with mortality in the high-income countries $(r=0.29, p<0.05)$.

In the low- and middle-income countries, the spread rate was not related with any parameters studied but mortality was negatively related with population density $(r=-$ $0.25, p<0.05)$ and GDP growth rate $(r=0.27, p<0.01)$. The difference between daytime maximum and night-time minimum temperature was positively related with mortality $(r=0.30, p<0.01)$ which highlights the influence of diurnal temperature variation 

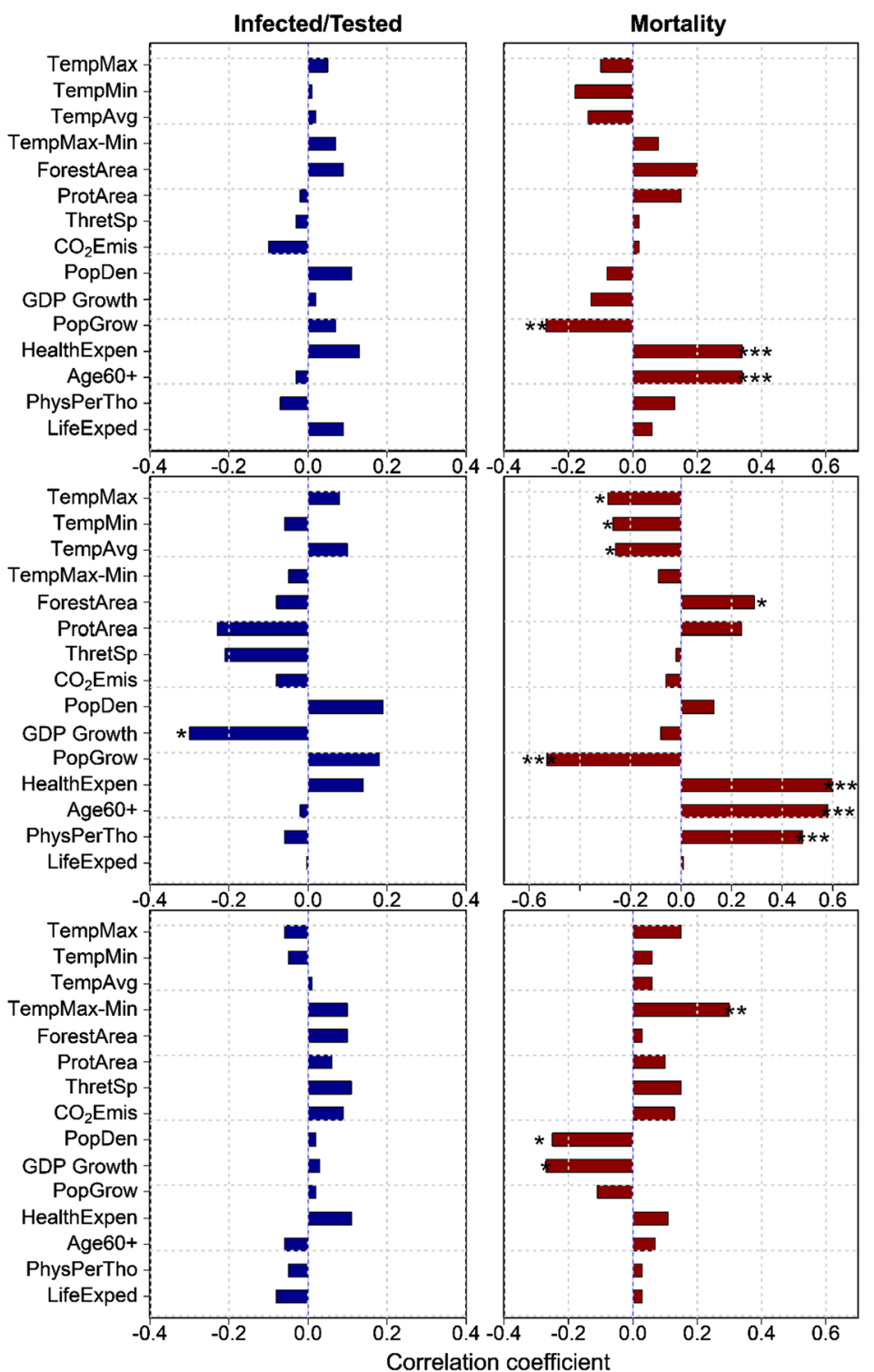

Fig. 3 Results of partial correlation analysis of COVID-19 spread rate and mortality with climatic, environmental and socio-economic parameters. For each explanatory variable, the duration after the first positive case was taken as controlling factor. * indicates correlation significant at $p<0.5, * *$ indicates correlation significant at $p<0.01, * * *$ indicates correlation significant at $p<0.001$

on mortality of COVID-19. When considered world temperature zones (Sayre et al. 2020), mortality rate was relatively higher in the cool and warm temperate zones than the tropical and subtropical zones (Fig. 4). Within the tropical and subtropical zones, mortality was high in the Caribbean region, whereas within the temperate zones, high mortality was observed in Europe. 


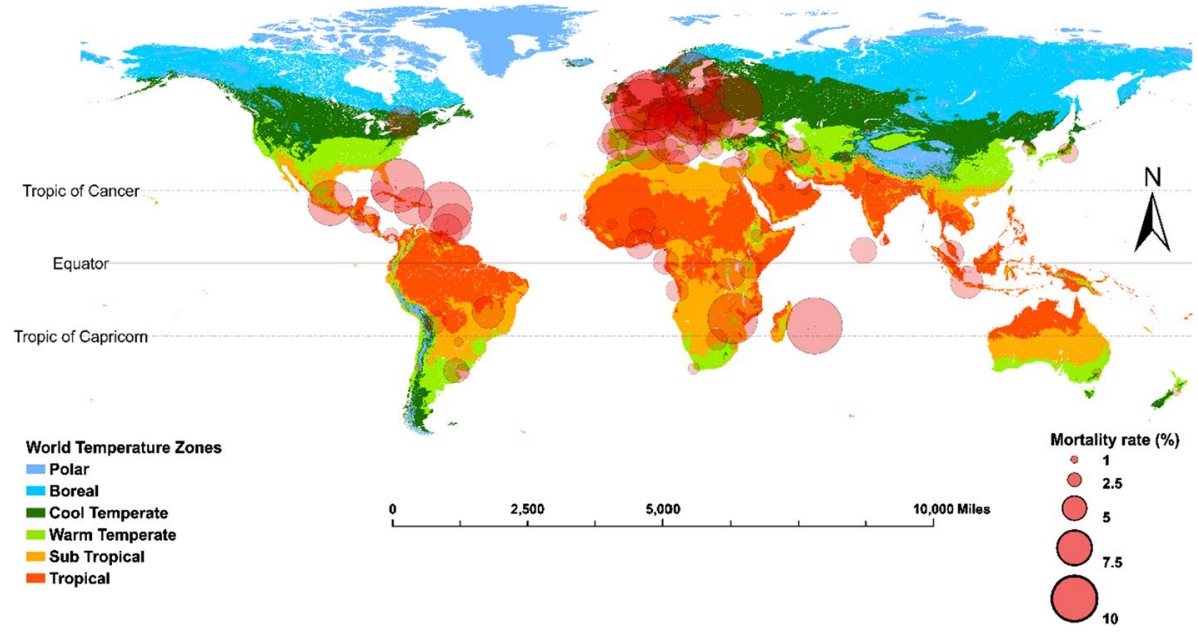

Fig. 4 Variation in mortality rate of COVID-19 among the countries of different temperature zones across the world. World temperature zone map was developed based on the six temperature domains given by Sayre et al. (2020)

The mixed effect modelling results revealed that inclusion of temperature in the model significantly improved the model skill predicting mortality in the low- and middle-income countries as observed lower AIC in the model with temperature $(\mathrm{AIC}=226)$ than the model without temperature $(\mathrm{AIC}=228)$ (Table 2, Fig. 5). Globally, temperature did not significantly improve model output of mixed effect models predicting mortality since AIC was not significantly lower in with-temperature model. Likewise, temperature caused no AIC variation between the models with and without temperature in the mortality prediction of high-income countries (Table 2).

Fig. 5 Comparison of linear mixed effect models without and with temperature predicting mortality rate in the low- and middle-income countries. Shaded areas represent $95 \%$ confidence interval

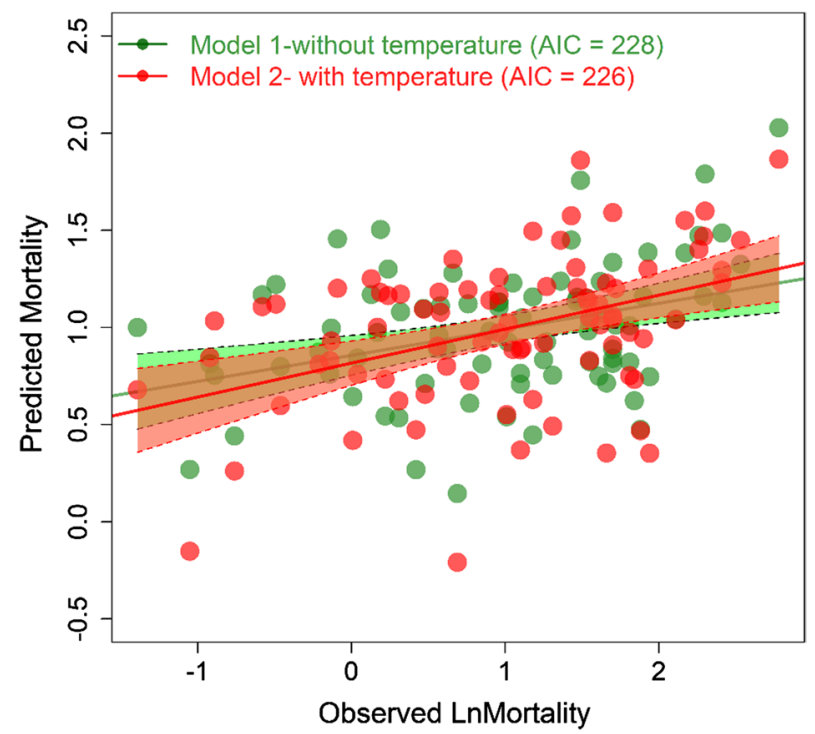




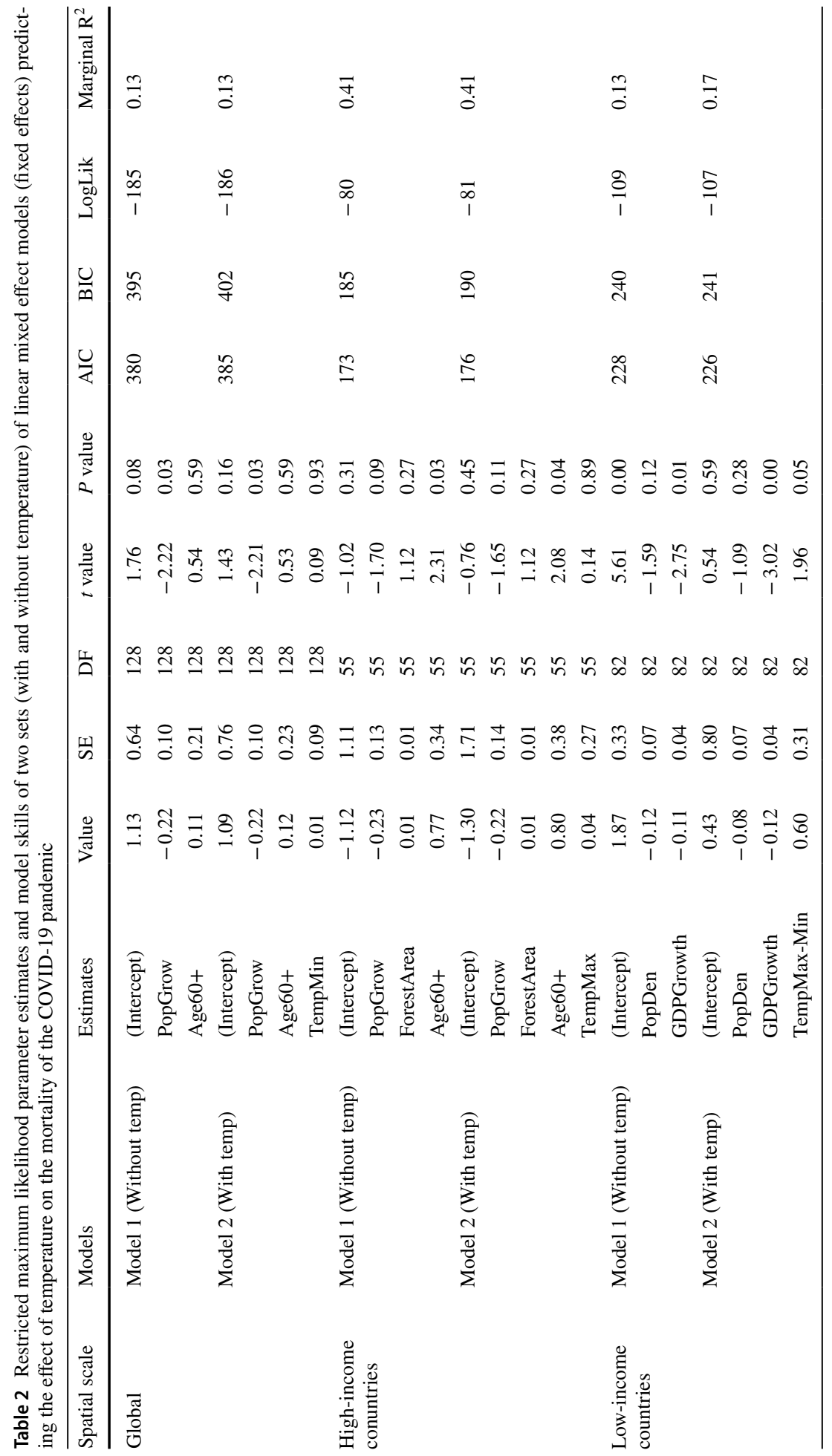




\section{Discussion}

The rate of spread and mortality of COVID-19 widely varied across the globe. We analysed a total of 15 factors (climatic, socio-economic and environmental) if they can explain the spatial variability of the spread rate and mortality of COVID-19. Spread rate of COVID19 was not related with any parameters at the global and regional scale. GDP growth rate was the only parameter which significantly and inversely related with the spread rate of COVID-19 in the countries with high-income economies (Fig. 3). The negative association between GDP growth rate and COVID-19 spread rate may lie in the fact that countries having higher growth rate were able to increase the test facilities rapidly so that infected people were possible to be identified and isolated leading a lower rate of spread. For example, Germany took the rapid initiative of doing more and more test resulting in lower infection as well as low mortality rate.

It was assumed earlier that warmer temperature may suppress the transmission rate of COVID-19. Many studies tested this hypothesis at the local and regional scale and found variable results. With increasing temperature, the confirmed cases were found to be decreased in Brazil, Turkey and China (Liu et al. 2020; Prata et al. 2020; Şahin 2020). On the other hand, some studies reported a direct relationship between temperature and COVID-19 transmission (Bashir et al. 2020; Menebo 2020; Tosepu et al. 2020; Xie and Zhu 2020). By analysing daily maximum, minimum and average temperature for the period from 1st January to 10th May 2020 and the spread rate averaged over the same period for 149 countries, we found no significant relationship between temperature and COVID-19 transmission at the global scale. Our results are however consistent with the findings of some other studies suggesting no influence of temperature on COVID-19 spread (Ahmadi et al. 2020; Iqbal et al. 2020; Yao et al. 2020).

Mortality was negatively related with population growth rate likely because of having high immune system in the countries with high population growth rate. Peoples in a country with high population growth rate are likely to have frequent infection by microorganism which may help develop hard immunity resulting in low mortality rate (Rook et al. 2006). Health expenditure, health physicians per thousand people and population over 60 years were strongly positively related with mortality in high-income countries. The relationship has been slightly dampened but still significant when analysed globally with a non-significant relationship in low- and middle-income countries. People aged over 60 years usually possess weak immune system and become high susceptible to virus infection (Bialek et al. 2020; Montecino-Rodriguez et al. 2013). The improved health system in developed countries increases life expectancy and hence the percentage of 60+ aged people becomes higher which may increase mortality risk in high-income countries. This is evident from a very strong positive relationship between health expenditure and $\%$ of $60+$ aged people globally and in high-income countries in our study (Fig. 6).

The mortality rate in the high-income countries was significantly negatively related with temperature. This finding indicates that SARS-CoV-2 is more active in low temperature than in high temperature. Similar findings were also found in some earlier studies (Anis 2020; Sajadi et al. 2020) which support that high temperature may suppress SARS-CoV-2. An earlier study also supported this assumption but the case was tested on influenza virus (Lowen et al. 2007). However, in the low- and middle-income countries, we observed a positive relationship of temperature with mortality (Fig. 3). This finding is consistent with one of the pioneer studies testing temperature effect on COVID-19 mortality in China (Ma et al. 2020). The variation of this response is likely 

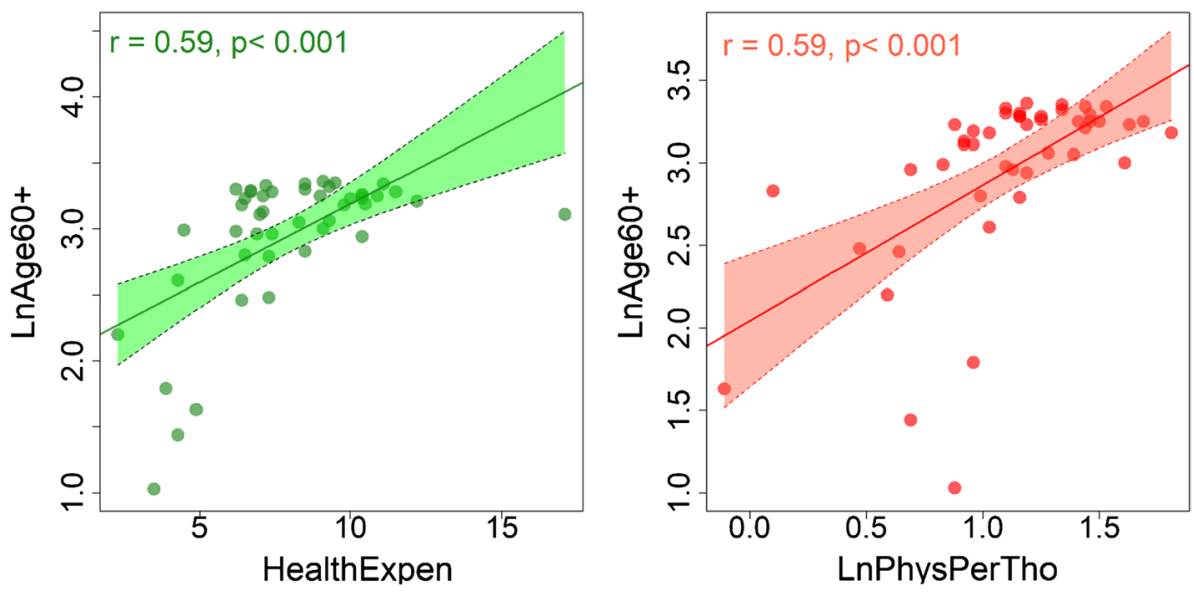

Fig. 6 Relation of health expenditure (\% of GDP) and number of physicians per thousand people with percentage of people over 60 years old in countries of high-income economies

to be linked with the genetic characteristics of SARS-CoV-2 in different regions. In our study, the difference between maximum and minimum temperature had a positive link with mortality in the low- and middle-income countries. This may imply that very high temperature at daytime and a very low temperature at night (diurnal temperature variation) increase the mortality risk. To confirm this result, we did additional analysis using linear mixed effect modelling. Inclusion of diurnal temperature variation into the mixed effect models improved model performance as we observed significantly lower AIC in the later model. (Table 2, Fig. 5).

Among the environmental variables protected area percentage, number of threatened species and $\mathrm{CO}_{2}$ emission showed no significant relation with the spread and mortality rate of COVID-19 at any regional and global scale. Forested area percentage, however, showed positive relation with mortality in the high-income countries. In the highincome countries, the percentage of forested area is quite high, e.g. $73 \%$ in Finland and $68 \%$ in Japan (https://data.un.org/). At the same time, due to the improved health care system, these countries have the highest percentage of 60+ years old people (Japan 34\%, Finland 28\%). Since 60+ years old people are more susceptible to COVID-19 (Davies et al. 2020), the mortality rate is high in the high-income countries leading a positive relationship between forested area and mortality rate in our study.

Overall, we provide evidence that temperature is not an important factor to explain the spatial variability of COVID-19 transmission at a global scale. However, temperature did explain the spatial variability of mortality particularly in the low- and middleincome countries. A strong positive relation of diurnal temperature variation with mortality in the low- and middle-income countries indicates that a very high temperature at daytime and a very low temperature at night may aggravate the mortality rate in these regions. In the countries with high-income economies, mortality rate is mainly dependent on the percentage of aged people (60+ years) which is higher in developed countries due to their improved health system.

Acknowledgements The authors sincerely acknowledge the supports provided by the colleagues during personal communication regarding the missing data. 


\section{Compliance with ethical standards}

Conflict of interest The authors declare that they have no conflict of interest.

\section{References}

Ahmadi, M., Sharifi, A., Dorosti, S., JafarzadeGhoushchi, S., \& Ghanbari, N. (2020). Investigation of effective climatology parameters on COVID-19 outbreak in Iran. Science of The Total Environment, 729, 138705. https://doi.org/10.1016/j.scitotenv.2020.138705.

Anis, A. (2020). The effect of temperature upon transmission of COVID-19: Australia and egypt case study. SSRN Electronic Journal. https://doi.org/10.2139/ssrn.3567639.

Atalan, A. (2020). Is the lockdown important to prevent the COVID-9 pandemic? Effects on psychology, environment and economy-perspective. Annals of Medicine and Surgery, 56, 38-42. https:// doi.org/10.1016/j.amsu.2020.06.010.

Bashir, M. F., Ma, B., Bilal, Komal, B., Bashir, M. A., Tan, D., et al. (2020). Correlation between climate indicators and COVID-19 pandemic in New York, USA. Science of The Total Environment, 728, 138835. https://doi.org/10.1016/j.scitotenv.2020.138835.

Bialek, S., Boundy, E., Bowen, V., Chow, N., Cohn, A., Dowling, N., et al. (2020). Severe outcomes among patients with coronavirus disease 2019 (COVID-19)-United States, february 12-march 16, 2020. Morbidity and Mortality Weekly Report. https://doi.org/10.15585/mmwr.mm6912e2.

Chan, J. F. W., Yuan, S., Kok, K. H., To, K. K. W., Chu, H., Yang, J., et al. (2020). A familial cluster of pneumonia associated with the 2019 novel coronavirus indicating person-to-person transmission: A study of a family cluster. The Lancet, 395, 514-523. https://doi.org/10.1016/S0140-6736(20)30154 -9 .

Chu, D. K. W., Pan, Y., Cheng, S. M. S., Hui, K. P. Y., Krishnan, P., Liu, Y., et al. (2020). Molecular diagnosis of a novel coronavirus (2019-nCoV) causing an outbreak of pneumonia. Clinical Chemistry, 66(4), 549-555. https://doi.org/10.1093/clinchem/hvaa029.

Davies, N. G., Klepac, P., Liu, Y., Prem, K., Jit, M., Pearson, C. A. B., et al. (2020). Age-dependent effects in the transmission and control of COVID-19 epidemics. Nature Medicine, 26(8), 12051211. https://doi.org/10.1038/s41591-020-0962-9.

Dong, E., Du, H., \& Gardner, L. (2020). An interactive web-based dashboard to track COVID-19 in real time. The Lancet Infectious Diseases, 20(5), 533-534. https://doi.org/10.1016/S1473 $-3099(20) 30120-1$.

Gorbalenya, A. E., Baker, S. C., Baric, R. S., de Groot, R. J., Drosten, C., Gulyaeva, A. A., et al. (2020). The species severe acute respiratory syndrome-related coronavirus: Classifying 2019-nCoV and naming it SARS-CoV-2. Nature Microbiology, 5, 536-544. https://doi.org/10.1038/s4156 4-020-0695-Z.

Harapan, H., Itoh, N., Yufika, A., Winardi, W., Keam, S., Te, H., et al. (2020). Coronavirus disease 2019 (COVID-19): A literature review. Journal of Infection and Public Health, 13(5), 667-673. https:// doi.org/10.1016/j.jiph.2020.03.019.

Huang, C., Wang, Y., Li, X., Ren, L., Zhao, J., Hu, Y., et al. (2020). Clinical features of patients infected with 2019 novel coronavirus in Wuhan China. The Lancet, 395(10223), 497-506. https://doi. org/10.1016/S0140-6736(20)30183-5.

IBM Corp. (2017). IBM SPSS statistics for windows version 25.0. Armonk, NY: IBM Corp.

Iqbal, N., Fareed, Z., Shahzad, F., He, X., Shahzad, U., \& Lina, M. (2020). The nexus between COVID19 , temperature and exchange rate in Wuhan city: New findings from partial and multiple wavelet coherence. Science of The Total Environment, 729, 138916. https://doi.org/10.1016/j.scito tenv.2020.138916.

Jahangiri, M., Jahangiri, M., \& Najafgholipour, M. (2020). The sensitivity and specificity analyses of ambient temperature and population size on the transmission rate of the novel coronavirus (COVID-19) in different provinces of Iran. Science of The Total Environment, 728, 138872. https:// doi.org/10.1016/j.scitotenv.2020.138872.

Jia, J. S., Lu, X., Yuan, Y., Xu, G., Jia, J., \& Christakis, N. A. (2020). Population flow drives spatiotemporal distribution of COVID-19 in China. Nature. https://doi.org/10.1038/s41586-020-2284-y.

Jin, J.-M., Bai, P., He, W., Wu, F., Liu, X.-F., Han, D.-M., et al. (2020). Gender differences in patients with COVID-19: Focus on severity and mortality. Frontiers in Public Health. https://doi. org/10.3389/fpubh.2020.00152. 
Li, Q., Guan, X., Wu, P., Wang, X., Zhou, L., Tong, Y., et al. (2020). Early transmission dynamics in Wuhan, China, of novel coronavirus-infected pneumonia. New England Journal of Medicine, 382(13), 1199-1207. https://doi.org/10.1056/NEJMoa2001316.

Liu, J., Zhou, J., Yao, J., Zhang, X., Li, L., Xu, X., et al. (2020). Impact of meteorological factors on the COVID-19 transmission: A multi-city study in China. Science of The Total Environment, 726, 138513. https://doi.org/10.1016/j.scitotenv.2020.138513.

Lowen, A. C., Mubareka, S., Steel, J., \& Palese, P. (2007). Influenza virus transmission is dependent on relative humidity and temperature. PLOS Pathogens, 3(10), e151. https://doi.org/10.1371/journ al.ppat.0030151.

Lu, R., Zhao, X., Li, J., Niu, P., Yang, B., Wu, H., et al. (2020). Genomic characterisation and epidemiology of 2019 novel coronavirus: Implications for virus origins and receptor binding. The Lancet, 395(10224), 565-574. https://doi.org/10.1016/S0140-6736(20)30251-8.

Ma, Y., Zhao, Y., Liu, J., He, X., Wang, B., Fu, S., et al. (2020). Effects of temperature variation and humidity on the death of COVID-19 in Wuhan, China. Science of The Total Environment, 724, 138226. https://doi.org/10.1016/j.scitotenv.2020.138226.

Menebo, M. M. (2020). Temperature and precipitation associate with Covid-19 new daily cases: A correlation study between weather and Covid-19 pandemic in Oslo, Norway. Science of The Total Environment, 737, 139659. https://doi.org/10.1016/j.scitotenv.2020.139659.

Montecino-Rodriguez, E., Berent-Maoz, B., \& Dorshkind, K. (2013). Causes, consequences, and reversal of immune system aging. The Journal of clinical investigation, 123(3), 958-965. https://doi. org/10.1172/JCI64096.

Prata, D. N., Rodrigues, W., \& Bermejo, P. H. (2020). Temperature significantly changes COVID-19 transmission in (sub)tropical cities of Brazil. Science of the Total Environment, 729, 138862. https ://doi.org/10.1016/j.scitotenv.2020.138862.

R Development Core Team (2019) R: A language and environment for statistical computing R Foundation for Statistical Computing, Vienna, Austria. R Foundation for Statistical Computing, Vienna, Austria.https://www.r-project.org/

Rook, G. A. W., Dheda, K., \& Zumla, A. (2006). Immune systems in developed and developing countries; implications for the design of vaccines that will work where BCG does not. Tuberculosis, 86, 152-162. https://doi.org/10.1016/j.tube.2006.01.018.

Şahin, M. (2020). Impact of weather on COVID-19 pandemic in Turkey. Science of The Total Environment, 728, 138810. https://doi.org/10.1016/j.scitotenv.2020.138810.

Sajadi, M. M., Habibzadeh, P., Vintzileos, A., Shokouhi, S., Miralles-Wilhelm, F., \& Amoroso, A. (2020). Temperature and latitude analysis to predict potential spread and seasonality for COVID19. SSRN Electronic Journal, Article in press. https://doi.org/10.2139/ssrn.3550308.

Sayre, R., Karagulle, D., Frye, C., Boucher, T., Wolff, N. H., Breyer, S., et al. (2020). An assessment of the representation of ecosystems in global protected areas using new maps of World Climate Regions and World Ecosystems. Global Ecology and Conservation, 21, e00860. https://doi. org/10.1016/j.gecco.2019.e00860.

Shammi, M., Bodrud-Doza, M., Islam, A. R. M. T., \& Rahman, M. M. (2020). Strategic assessment of COVID-19 pandemic in Bangladesh: Comparative lockdown scenario analysis, public perception, and management for sustainability. Environment, Development and Sustainability. https://doi. org/10.1007/s10668-020-00867-y.

Shereen, M. A., Khan, S., Kazmi, A., Bashir, N., \& Siddique, R. (2020). COVID-19 infection: Origin, transmission, and characteristics of human coronaviruses. Journal of Advanced Research, 24, 91-98. https://doi.org/10.1016/j.jare.2020.03.005.

Song, W.-Y., Zang, P., Ding, Z.-X., Fang, X.-Y., Zhu, L.-G., Zhu, Y., et al. (2020). Massive migration promotes the early spread of COVID-19 in China: A study based on a scale-free network. Infectious Diseases of Poverty, 9(1), 109. https://doi.org/10.1186/s40249-020-00722-2.

Tosepu, R., Gunawan, J., Effendy, D. S., Ahmad, L. O. A. I., Lestari, H., Bahar, H., et al. (2020). Correlation between weather and Covid-19 pandemic in Jakarta Indonesia. Science of The Total Environment, 725, 138436. https://doi.org/10.1016/j.scitotenv.2020.138436.

Xie, J., \& Zhu, Y. (2020). Association between ambient temperature and COVID-19 infection in 122 cities from China. Science of The Total Environment, 724, 138201. https://doi.org/10.1016/j.scito tenv.2020.138201.

Yao, Y., Pan, J., Liu, Z., Meng, X., Wang, W., Kan, H., et al. (2020). No association of COVID-19 transmission with temperature or UV radiation in Chinese cities. European Respiratory Journal, 55(5), 2000517. https://doi.org/10.1183/13993003.00517-2020. 
Yu, W. B., Tang, G. D., Zhang, L., \& Corlett, R. T. (2020). Decoding the evolution and transmissions of the novel pneumonia coronavirus (SARS-CoV-2/HCoV-19) using whole genomic data. Zoological Research, 41(3), 247-257. https://doi.org/10.24272/j.issn.2095-8137.2020.022.

Zhou, P., Yang, X.-L., Wang, X.-G., Hu, B., Zhang, L., Zhang, W., et al. (2020). A pneumonia outbreak associated with a new coronavirus of probable bat origin. Nature, 579(7798), 270-273. https://doi. org/10.1038/s41586-020-2012-7.

Publisher's Note Springer Nature remains neutral with regard to jurisdictional claims in published maps and institutional affiliations. 